\title{
SANEAMENTO EM COMUNIDADES TRADICIONAIS: COMO GARANTIR OS DIREITOS HUMANOS?
}

\section{WATER AND SANITATION IN TRADITIONAL COMMUNITIES: HOW TO GUARANTEE HUMAN RIGHTS?}

\author{
Bárbarah Brenda Silva ${ }^{(1)}$ \\ Cientista socioambiental, mestra e doutoranda pelo Programa de Pós-Graduação em Saneamento, Meio Ambiente e \\ Recursos Hídricos (PPG-SMARH/UFMG). \\ Caroline Pedrosa Alves ${ }^{(2)}$ \\ Graduanda em Engenharia Civil (UFMG). \\ Júlio Cézar Lima ${ }^{(3)}$ \\ Graduando em Engenharia Civil (UFMG). \\ Sonaly Rezende ${ }^{(4)}$ \\ Professora associada do Departamento de Engenharia Sanitária e Ambiental da UFMG. Engenheira Civil, mestra pelo \\ Programa de Pós-Graduação em Saneamento, Meio Ambiente e Recursos Hídricos (PPG-SMARH/UFMG), doutora \\ pelo Centro de Desenvolvimento e Planejamento Regional (Cedeplar/UFMG).
}

\section{E-mail ${ }^{(1)}$ : barbarahbibs@hotmail.com}

\section{RESUMO}

Entre os povos e comunidades tradicionais, figuram as comunidades quilombolas. Considerando a importância de se garantir os DHAS para estas comunidades, tendo em conta as suas especificidades, este artigo busca analisar aspectos relativos ao acesso à água e ao esgotamento sanitário em duas comunidades quilombolas situadas em Minas Gerais. Para isso, são mobilizados conteúdos que sintetizam as suas demandas, interpretando-as segundo os critérios dos DHAS. Observou-se que o reconhecimento destes povos pela Constituição Federal e pelas Nações Unidas ainda não é capaz de garantir o usufruto dos seus direitos inalienáveis. A relação de pertencimento, os vínculos familiares, de compadrio e colaboração são aspectos que influenciam o comportamento e o vínculo estreito dos sujeitos com o ambiente e, consequentemente, as práticas sanitárias. Assim, as estruturas sanitárias precisam ser coerentes com as tradições de seus demandantes.

\section{ABSTRACT}

Traditional peoples and communities include Quilombolas. Considering the importance of DHAS for these communities this article seeks to analyze aspects related to access to water and sanitation in two Quilombola communities of Minas Gerais. Contents are mobilized that synthesize their demands, interpreting them according to the criteria of the DHAS. The recognition of these peoples by the Federal Constitution and the United Nations is not yet able to guarantee the enjoyment of their inalienable rights. The relationship of belonging, family ties and collaboration are aspects that influence the behavior and close bond of the subjects with the environment and, consequently, health practices. Thus, sanitary structures need to be consistent with the traditions of their claimants.
\end{abstract}

Palavras-chave: Água. Esgotamento sanitário. Ancestralidade. Cultura. Ruralidade.

Key words: Water. Sanitation. Ancestry. Culture. Rurally.

\section{INTRODUÇÃO}

Os povos e comunidades tradicionais foram reconhecidos em seu direito de pertencerem a grupos sociais auto organizados. A identidade desses grupos é a identidade de suas lutas e conquistas. Para eles, a obtenção de água, a possibilidade de usá-la em quantidade suficiente e a necessidade de tratar os esgotos gerados são demandas entendidas como coletivas, pela condição de vínculo ancestral reprodutor da coesão social, pautada na cultura e tradição e mantenedora de um alinhamento de valores que resulta em ações colaborativas. 
Entre os povos e comunidades tradicionais, figuram as comunidades quilombolas. No Brasil, tais comunidades totalizam 3.386, estando 2.744 certificadas. A maior parte das comunidades certificadas é encontrada no Nordeste (2.138), seguida do Sudeste (527), Norte (366), Sul (191) e Centro-Oeste (164) (Fundação Cultural Palmares, 2019). O Relatório sobre os Direitos dos Povos e Comunidades Tradicionais $(\mathrm{CNDH}, 2018)$ apresenta as violações sofridas por quilombolas, enfatizando o desrespeito à sua tradicionalidade e autodeterminação, e o processo de desterritorialização ao qual estão continuamente sujeitos. Sustentado pela negação à regularização fundiária, tal processo tem resultado no aumento da sujeição a expropriações e grilagem.

Considerando a importância de se garantir os Direitos Humanos à Água e ao Saneamento (DHAS) para as comunidades quilombolas, tendo em conta as suas especificidades, este artigo busca analisar aspectos relativos ao acesso à água e ao esgotamento sanitário em duas comunidades quilombolas, à luz de aspectos delineadores de suas identidades culturais e modos de vida, assim como do referencial teórico dos DHAS. Para isso são mobilizados conteúdos que sintetizam as demandas dos povos e comunidades tradicionais quilombolas, interpretadas segundo os critérios dos DHAS; e apresentados resultados obtidos junto às populações das comunidades de Vargem da Lua e de Quilombo, ambas pertencentes ao Estado de Minas Gerais.

\section{METODOLOGIA}

O material empregado na análise abrange informações secundárias oriundas de marcos legais (Constituição Federal de 1988 e os Decretos atinentes à Política Nacional de Desenvolvimento Sustentável dos Povos e Comunidades Tradicionais); o marco dos DHAS; relatórios municipais e informações do IBGE. Envolve também a observação participante nas comunidades de Vargem da Lua (MG) e Quilombo (MG). A análise de conteúdo temática representa a técnica utilizada no tratamento dos dados obtidos. Os temas explorados correspondem aos seguintes critérios de DHAS: disponibilidade, qualidade e segurança, aceitabilidade e acessibilidade física e financeira.

\section{RESULTADOS E DISCUSSÃO}

\section{1 - DHAS, tradição e cultura ancestral}

Os DHAS foram instituídos em 2010, a partir da aprovação, pela ONU, da Resolução A/RES/64/292. A discussão inicial da qual derivou a confirmação desses direitos é representada pelo Comentário Geral $n^{\circ} 157$, de 2002, no qual o Comitê de Direitos Econômicos, Sociais e Culturais, reconhece a obrigatoriedade de países signatários da ONU se comprometerem legalmente com a sua realização.

Aspectos culturais estão no ponto de partida dos DHAS por representarem a valorização de costumes que sustentam os distintos modos de vida, e por guardarem lugar para condições modificadoras de pensar e agir em uma sociedade. A formulação antropológica de Edward B. Taylor, pioneiro nessa vertente, abarca conhecimento, crenças, arte, normas e costumes dentro de uma sociedade. Nessa formulação, cultura representa um conjunto de ideias, comportamentos, símbolos e práticas sociais aprendidos e repassados de geração em geração por meio da vida em sociedade (TYLOR, 1871).

A Constituição de uma Nação é um fenômeno cultural, que, em tese, reflete todas as condições inerentes à sua formação, movida por crenças e racionalidades, e no contexto ambiental e econômico de uma sociedade, conduzindo ao princípio de organização que dispõe sobre direitos e deveres individuais e coletivos (CARVALHO, 2018). A Constituição Federal de 1988 prevê em seu artigo 216 que "Constituem patrimônio cultural brasileiro os bens de natureza material e imaterial, tomados individualmente ou em conjunto, portadores de referência à identidade, à ação, à memória 
dos diferentes grupos formadores da sociedade brasileira" (BRASIL, 1988). Dentre os referidos bens, estão incluídos "os modos de criar, fazer e viver", com referência explícita às criações científicas, artísticas e tecnológicas. O texto constitucional reconhece, portanto, o multiculturalismo e volta-se à preservação da memória e do acúmulo de saberes por diferentes grupos identitários que representam o patrimônio cultural brasileiro.

Data de 2004 o Decreto que institui a Comissão Nacional de Desenvolvimento Sustentável das Comunidades Tradicionais e dá outras providências. Este Decreto foi revogado em 2006, sendo em 2007, lançado o Decreto n 6.040, que institui a Política Nacional de Desenvolvimento Sustentável dos Povos e Comunidades Tradicionais, coordenada pela Comissão Nacional. Os territórios tradicionais passam a corresponder a espaços necessários à reprodução cultural, social e econômica de seus habitantes, utilizados de forma permanente ou temporária. A referida Política está centrada no desenvolvimento sustentável e no reconhecimento, fortalecimento e garantia dos diretos territoriais, sociais, ambientais, econômicos e culturais dos povos e comunidades tradicionais (PCT), enfatizando a importância do respeito e valorização à sua identidade, formas de organização e instituições. Nos incisos I, II e IV, do art. $3^{\circ}$, o Decreto de 2007 prevê a garantia de acesso aos recursos naturais que tradicionalmente utilizam para sua reprodução física, cultural e econômica; a solução e/ou minimização dos conflitos gerados pela implantação de Unidades de Conservação de Proteção Integral; e a garantia dos direitos dos povos e das comunidades tradicionais afetados direta ou indiretamente por projetos, obras e empreendimentos.

De acordo com o Mapeamento de povos e comunidades tradicionais em Minas Gerais: visibilização e inclusão sociopolítica, desenvolvido pelo Grupo de Estudos em Temáticas Ambientais (GESTA/UFMG), "os povos e comunidades tradicionais são grupos culturalmente diferenciados, que possuem condições sociais, culturais e econômicas próprias, mantendo relações específicas com o território e com o meio ambiente no qual estão inseridos." (MPMG, 2014). Os PCT apresentam relação de respeito com o território que habitam, valorizando seus recursos naturais para além da perspectiva econômica. Em seu processo de produção, PCT ditam ritmo e lógica próprios, fortemente pautados na ancestralidade em detrimento de pressupostos meramente técnicos. Nesses grupos prepondera a agregação de até quatro gerações de uma mesma família: a casa dos avós é também a dos filhos, netos, bisnetos e agregados. A instituição familiar é a base de organização da vida em comunidade (HEREDIA; GARCIA, 1971; ALMEIDA, 1986).

A entrada das pautas da PCT na agenda governamental é bastante associada à salubridade ambiental. Merece destaque a Política Nacional de Saúde Integral das Populações do Campo, da Floresta e das Águas (PNSIPCF), publicada em 2011, com o objetivo de garantir o direito e o acesso à saúde por meio do Sistema Único de Saúde (SUS), segundo os princípios de equidade, universalidade e integralidade, enfatizando as peculiaridades, especificidades e necessidades em saúde dos PCT. A PNSIPCF foi formulada pelo Ministério da Saúde e contou com participação dos movimentos sociais, por meio do Grupo da Terra, instituído em 2005. De acordo com o Observatório Saúde, Campo, Floresta e Águas (OBTEIA), a pauta do Grupo da Terra revela a defesa dos modos de vida, produção e reprodução social pautados na relação interpessoal e com a terra e a água, de "grupos que habitam ou usam reservas extrativistas em áreas florestais ou aquáticas, camponesas/es, agricultoras/es familiares, trabalhadoras/es rurais assentadas/os ou acampadas/os, trabalhadoras/es assalariadas/os e temporárias/os" (MINISTÉRIO DA SAÚDE, 2011).

\section{2 - A realidade sanitária de comunidades quilombolas na perspectiva dos DHAS}

A ótica dos direitos humanos cria condições para o planejamento de ações respaldadas na responsabilização do poder público, que deve garantir que todas as pessoas tenham acesso equânime a serviços de água e esgotamento sanitário, sem discriminação, que haja transparência na 
prestação de serviços, disponibilização de informações aos usuários e que estes sejam instados a participarem de decisões inerentes à gestão.

$\mathrm{O}$ acesso à água deve garantir a disponibilidade deste recurso em quantidade suficiente para o atendimento das demandas individuais e domiciliares, cumprindo os requisitos de qualidade, continuidade e segurança, demonstrando não haver risco à saúde da população. Todos os diferentes tipos de usos requeridos precisam ser atendidos. Para tanto, é preciso observar que, dentre os usos, podem constar a utilização no âmbito individual e coletivo, como em rituais ou momentos específicos onde a utilização da água é necessária.

Entre os povos e comunidades tradicionais, a aceitabilidade da água resulta de interpretações de cor, cheiro e gosto, aspectos influenciados pelo saber local, pelas práticas culturais e pela percepção sobre alterações ambientais. O uso rotineiro de múltiplas fontes de água e sua hierarquização segundo a qualidade e sua separação para diferentes usos, tão comuns em áreas rurais, se baseia em julgamento rotineiro de sua qualidade. Tal julgamento reflete aspectos da ancestralidade, que resulta da vivência e convívio das gerações com o espaço, criando modos de produção e reprodução de costumes específicos que influenciam a relação com a água (LEITE, 2016).

A escolha das fontes de água pode depender de critérios intrínsecos a cada comunidade tradicional. Fatores como forma de acesso, distância, localização e a perspectiva cutural (como a criação de mitos e estórias) podem delimitar esta escolha. Ademais, as fontes acessadas dependem das demandas, em termos de quantidade e qualidade, e da forma como a água é utilizada. A acessibilidade e distância a algumas das fontes nem sempre é facilitada, havendo, por isso, demandas atendidas no local de captação (lavagem de roupas, por exemplo). Tal estratégia é inerente a grupos que possuem vínculos familiares, revelando condutas que denotam proteção mútua, trocas de experiências e solidariedade, importantes para a preservação da cultura e, portanto, valorizada em comunidades quilombolas. Não obstante, os quilombos, assim como outros tipos de comunidades tradicionais, possuem pessoas com necessidades diferentes (como idosos, pessoas com deficiência, mulheres e crianças) que precisam de infraestruturas que se adequem às suas particularidades. No caso da instalação das estruturas sanitárias, atenção especial deve ser dada à escolha do local e o tipo de solução. $\mathrm{O}$ afastamento/disposição das escretas e a localização da estrutura em relação às casas devem condizer com o entendimento de aspectos culturais relacionados à práticas e crenças relativas ao sagrado ou ao extrafísico.

A acessibilidade econômica, por sua vez, tem importância central no contexto tratado, onde é costume o compartilhamento de recursos materiais e imateriais. Deste modo, os serviços devem estar disponíveis a preço acessível a toda população, e o pagamento não deve contribuir para que as famílias necessitem destinar recursos empregados na aquisição de alimentos, em educação e saúde, no pagamento de taxas dos próprios domicílios e/ou em apoio a outras famílias.

Outro fator importante, relacionado à segurança, é que muitos quilombos ainda não foram delimitados legalmente ou inserem-se em contextos de disputa constante pelo uso da terra, seja por empreendimentos imobiliários, urbanisticos, agroindustriais, minerários ou pelo potencial economico da área que ocupam. Assim, além de consistirem em áreas que são invisibilizadas pelas políticas públicas, tal interferência e pressão externa traduzem-se em ameaças que colocam em cheque a relação cultural que os povos tradicionais desenvolvem com o território e com os recursos naturais presentes, ampliando também os estigmas e as intolerâncias étnicas (COSTA FILHO, 2012; LEITE, 2016). O acesso a fontes de água, por exemplo, pode ser restringido por cercamentos ou ameaças à integridade física dos moradores, resultado de disputas e conflitos pelo uso da água. Assim, o tipo ou a localização das soluções sanitárias precisam estar dessociadas da influência destes agentes externos para que o cumprimento dos DHAS seja garantido.

A realidade das comunidades quilombolas e sua relação com a água, abarca dimensões que as diferenciam, em termos de demandas, de outras coletividades. A salubridade ambiental tem, cada 
vez mais, reforçado a importância das mobilizações locais por meio de grupos sociais com identificação étnica e coletiva como dimensão de suas lutas políticas por direito a terras e acesso aos recursos naturais, que resultaram na política de reconhecimento dos PCT. Entretanto, no atual contexto, está em vigor o Decreto $n^{\circ}$ 9.759/2019, que extingue e estabelece diretrizes, regras e limitações para colegiados da administração pública federal. Diante desta ameaça é cada vez mais importante reforçar o debate envolvendo os DHAS para povos e comunidades tradicionais.

A comunidade rural Vargem da Lua possui características quilombolas remanescentes, todavia ainda não é reconhecida pela Fundação Cultural Palmares. Ela situa-se nos limites de São Gonçalo do Rio Abaixo e dista aproximadamente oito quilômetros da sede municipal, com facilidade de acesso por estrada parcialmente pavimentada. Com cerca de duzentos habitantes e 45 domicílios, Vargem da Lua encontra-se em zona de autossalvamento de uma das barragens de rejeitos da mina de Brucutu, uma das maiores em funcionamento do Brasil. Isso significa que a comunidade fica localizada imediatamente a jusante da barragem, de forma que se considera não haver tempo hábil para evacuação da população em caso de acidente ou rompimento.

Todos os seus membros possuem relações de parentesco e a renda da maioria advém da agricultura familiar. A forma de produção da comunidade depende diretamente da disponibilidade hídrica local para a sua continuidade, todavia, a instalação da planta da mineradora ocasionou o rebaixamento do lençol freático, secando nascentes e poços profundos anteriormente utilizados. Para atenuar os efeitos negativos nos cursos d'água e o comprometimento da produção da vida dos/as habitantes de Vargem da Lua, a Prefeitura de São Gonçalo do Rio Abaixo disponibilizou a água proveniente de um poço nas suas proximidades, que é bombeada e distribuída em todas as residências.

Quilombo é uma comunidade pertencente ao município de Sabinópolis (MG) e dista 29 km da sede municipal. $\mathrm{O}$ acesso se dá de forma precária por meio de estrada não pavimentada. $\mathrm{O}$ distrito e a comunidade possuem sistema de abastecimento de água advinda de poço profundo, não havendo tratamento. Com cerca de 125 pessoas e 50 domicílios, seus/suas moradores/as se dedicam à agricultura familiar. O principal córrego da região é receptor da água de 47 nascentes, todavia, a intensa degradação do solo proveniente da prática agropecuária na região (criação de gado de corte, de leite e plantio de eucalipto), culminou na diminuição da disponibilidade hídrica e a interferência na qualidade das águas.

Em 2003, a prefeitura de Sabinópolis realizou a instalação do sistema de coleta de esgotos na área urbana, mas há entupimentos e quebras constantes das manilhas (feitas de barro), além de não contar com estação de tratamento dos efluentes, que são lançados diretamente no curso d'água. Tal obra, fez com que o esgoto, anteriormente destinado a fossas ou lançado de forma difusa no córrego, passasse a ser lançado de forma concentrada em um ponto, o que ampliou consideravelmente a carga poluidora no corpo hídrico. Desta forma, as práticas cotidianas dos moradores e sua relação com o córrego modificaram-se. Atividades como o nado, a pesca, a lavagem de roupas e a utilização da água para consumo tiverem que ser interrompidas, ocasionando a perda de costumes tradicionais.

O comprometimento dos recursos hídricos e os impactos negativos vivenciados pelos quilombolas de Vargem da Lua e Quilombo culminam no comprometimeto do acesso à água, inviabilizam a produção familiar e comprometem a produção e reprodução da vida com bem estar e qualidade. As formas diversas de exprolação do território ao qual pertencem e/ou convivem seguem a proposta hegemônica de desenvolvimento, que, segundo Zhouri e Valencio (2014) agrava a existência de injustiças ambientais e relativizam o acesso de direitos básicos da pessoa humana e dos sujeitos coletivos, especialmente os vulnerabilizados. Apesar dos quilombolas e demais grupos tradicionais afirmarem seu direito à existência com base na Constituição Federal e em declarações das Nações Unidas, na prática, são visíveis episódios de relativização dos seus direitos inalienáveis. As soluções sanitárias culminam, então, em um quadro histórico de consequências negativas advindas de 
padrões simplificadores e que reduzem as complexidades encontradas em campo, implicando na não-conformidade com os princípios normativos dos DHAS. Devido a esta invisibilização, urge a necessidade da evidenciação de direitos básicos a determinadas coletividades, dentre elas, os quilombolas.

\section{CONCLUSÕES}

O reconhecimento legal dos quilombolas como sujeitos sociais e de direitos é relativamente recente e ainda insuficiente para superar padrões de repetição de negação de direitos de coletividades. Muitas vezes, a delimitação total da área envolve interesses de agentes externos que implicam em ameaças constantes, insegurança, violência simbólica e material, comprometendo a produção e reprodução da vida destes povos com todas as suas particularidades. A relação de pertencimento, os vínculos familiares, de compadrio e coletividade são aspectos que influenciam o comportamento e o vínculo estreito dos sujeitos com o ambiente. Assim, as estruturas sanitárias precisam ser coerentes com costumes tradicionais que influenciam sua localização, o tipo de solução praticada, seu uso e perenidade e sustentabilidade ao longo dos anos. Por meio dos estudos de caso, notam-se diversas não-conformidades relacionadas aos DHAS. Tais aspectos variam desde a invisibilização da presença e vida dos povos quilombolas, em detrimento de grandes empreendimetos, bem como ao comprometimento das suas demandas relacionadas à água e ao esgotamento sanitário. Neste sentido, tornam-se fundamentais os exemplos provenientes das realidades locais para se perceber o que está em jogo nas diversas situações analisadas, suas dimensões, articulações e formas.

\section{REFERÊNCIAS}

ALMEIDA, M. W. B. de. Redescobrindo a família rural. Revista Brasileira de Ciências Sociais. 1986.

BRASIL. Constituição (1988). Constituição da República Federativa do Brasil. Brasília, DF: Senado Federal: Centro Gráfico, 1988.

CALEGARE, M. G. A; HIGUCHI, M. I. G; BRUNO, A. C. S. Povos e comunidades tradicionais: das áreas protegidas à visibilidade política de grupos sociais portadores de identidade étnica e coletiva. Ambiente \& Sociedade, Vol.17 (3), p.115-134. 2014.

CARVALHO, M; S. Cultura, Constituição e Direitos Culturais. In: CUNHA FILHO, F. H.; BOTELHO, I; SEVERINO, J. R. (organizadores). Direitos culturais. Salvador: EDUFBA, 2018. 245 p. Disponível em: http://repositorio.ufba.br/ri/handle/ri/26054; acesso em: set 2021.

COSTA FILHO, Aderval. 2012. Identificação e Delimitação de territórios indígenas e quilombolas: conflitos e riscos na prática pericial antropológica. In: Andréa Zhouri (Org.). Desenvolvimento, reconhecimento de direitos e conflitos territoriais. Brasília: ABA, 2012 (p. 332-351).

GOMES, F. dos S. Mocambos e quilombos: uma história do campesinato negro no Brasil. São Paulo: Claro Enigma, 2015.

HEREDIA, B.; GARCIA Jr, A. Trabalho familiar e campesinato. América Latina. 1971.

JACCOUD, L. O combate ao racismo e à desigualdade: o desafio das Políticas Públicas de promoção da igualdade racial. In: THEODORO, M. (org.). As políticas públicas e a desigualdade racial no Brasil: 120 anos após a abolição. Brasília: Ipea, 2008. p. 131-166.

LEITE, I. B. Diásporas africanas e direitos territoriais: as várias dimensões do quilombo no Brasil. In: Osvaldo Martins de Oliveira (Org.). Direitos quilombolas \& dever de Estado em 25 anos da Constituição Federal de 1988. Rio de Janeiro: ABA, 2016. Pp. 289-304. 


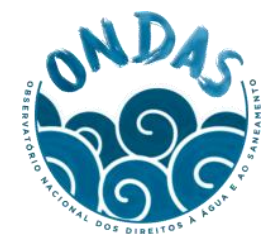

MINISTÉRIO DA SAÚDE. Portaria No 2.866, de 2 de dezembro de 2011. Institui, no âmbito do Sistema Único de Saúde (SUS), a Política Nacional de Saúde Integral das Populações do Campo e da Floresta (PNSIPCF).

Ministério Público de Minas Gerais. Direitos dos povos e comunidades tradicionais. 2014.

TYLOR, E. B. Primitive Culture. Inglaterra: Gordon Press, 1871.

ZHOURI, Andréa; VALENCIO, Norma (Org.). Formas de matar, de morrer e de resistir: limites da resolução negociada de conflitos ambientais. Belo Horizonte: UFMG, 2014. 